PERSPECTIVE OPEN

\title{
Interphase engineering of reactive metal surfaces using ionic liquids and deep eutectic solvents-from corrosion control to next-generation batteries
}

\author{
Maria Forsyth ${ }^{1}$, Patrick C. Howlett ${ }^{1}$, Anthony E. Somers ${ }^{1}$, Douglas R. MacFarlane ${ }^{2}$ and Andrew Basile (iD)
}

Ionic liquids are unique solvents composed entirely of ions and have recently been considered for applications ranging from synthesis, separations, electrochemical devices, tribology and corrosion. In this perspective, we summarise the literature, and look at the future prospects, surrounding the use of ionic liquids in the engineering of interphases to control charge transport thereby leading to improved performance of high-energy density batteries, including $\mathrm{Mg}$, $\mathrm{Li}$ and $\mathrm{Na}$ metal as well as corrosion protection of reactive engineering alloys, such as aluminium, magnesium and steel alloys. The ability to create task-specific ionic liquids by controlling the chemistry of either the anion or the cation means that interphases can be engineered for specific substrates and applications. Thus far, fluorine containing anions, such as bis(trifluoromethane) sulfonamide and its analogues, have been favoured for controlling the conductive solid-electrolyte interphase layer on $\mathrm{Li}$ and $\mathrm{Na}$, while ionic liquids containing organophosphate anions have been used to form nanometre thick protective interphases on Mg alloys. Recently, ionic liquids based on carboxylate anions have also been shown to provide excellent corrosion inhibition for steel. In the search for cost-effective solutions, a relatively new class of ionic liquids, termed deep eutectic solvents, have also been explored as potential media for controlling surface films on reactive metals. The deep eutectic solvents class of ionic liquid materials offers many possible combinations of chemistry that can be targeted to produce desired properties in this context.

npj Materials Degradation (2017)1:18; doi:10.1038/s41529-017-0016-z

\section{INTRODUCTION}

lonic liquids (ILs) have become increasingly of interest in engineering applications, including chemical processes, ${ }^{1,2} \mathrm{CO}_{2}$ capture $^{3,4}$ lubrication, ${ }^{5-7}$ electrochemical devices ${ }^{8-11}$ and corrosion protection. ${ }^{12-16}$ Their desirable properties can include low volatility, chemical and electrochemical stability and they can be potentially more environmental friendly and biologically more compatible. ${ }^{17}$ All these make them ideal replacements for more traditional solvents or surface treatments. The interest in ILs from both the research and application perspective has seen enormous growth over the past decade or so with more than 30,000 research articles and over 4000 patents filed over the past 5 years. The increased use of ILs, as solvents and heat transfer fluids for example, has also seen research into their corrosiveness and the susceptibility of common engineering metals to corrosion by ionic liquids under various conditions has been investigated. ${ }^{18,19}$ This has demonstrated that for some ionic liquid/metal combinations, more extensive corrosion can occur, whereas other combinations lead to passivation of the metal, as was demonstrated for magnesium alloys and discussed below.

Deep eutectic solvents (DES) have also recently been explored as potentially inexpensive media in the same context. Unlike conventional solvents which typically have volatility and may be chemically/electrochemically reactive, DES materials display many of the favourable properties of ILs. DES are prepared by combining a hydrogen bond donor and a hydrogen bond acceptor, which may in themselves be solid materials or volatile solvents, to produce a room temperature liquid, whereby essentially the same low volatility and chemical stability as in ILs can be achieved, albeit with a lower electrochemical window. ${ }^{20}$ One of the most common DES materials has been the combination of cholinium chloride with urea (see Fig. 1). In the context of this paper, this material has been used as a solvent for electroplating of $\mathrm{Zn}$ for example. ${ }^{21}$

Figure 1 presents a summary of the structures and nomenclature of some of the important ionic liquid cations and anions (as well as DES) considered thus far. In this perspective, we will summarise the key literature pertaining to the use of ionic liquids in controlling the electrochemistry of reactive metals, including $\mathrm{Li}$, $\mathrm{Na}$ and $\mathrm{Mg}$, for energy storage and corrosion control. We will then consider the future directions of this important field with respect to engineering the interphases of reactive surfaces to optimise performance and discover new applications.

\section{PROTECTING METAL BATTERY ANODES VIA SOLID-ELECTROLYTE INTERPHASE (SEI) FORMATION}

Air and moisture stable ionic liquids have been utilised in energy storage research since their introduction as promising electrolytes for lithium metal batteries since the early $1990 \mathrm{~s}^{22-26}$ Prior to that, chloroaluminate-based ionic liquids combined with the imidazolium cation were extensively investigated by Wilkes as potential battery electrolytes, however, these presented challenges with

\footnotetext{
${ }^{1}$ Institute for Frontier Materials and Australian Centre of Excellence for Electromaterials Science, Deakin University, 221 Burwood Highway, Burwood 3125 VIC, Australia and ${ }^{2}$ School of Chemistry, Monash University, Clayton 3800 VIC, Australia

Correspondence: Maria Forsyth (maria.forsyth@deakin.edu.au)
}

Received: 19 May 2017 Revised: 14 July 2017 Accepted: 25 July 2017

Published online: 13 November 2017 


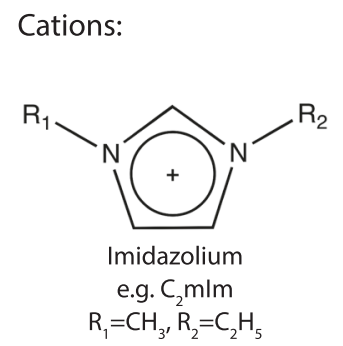<smiles>[R][N+]1([R])CCCC1</smiles>

Pyrrolidonium e.g. $\mathrm{C}_{3} \mathrm{mPyr}$ $\mathrm{R}_{1}=\mathrm{CH}_{3}, \mathrm{R}_{2}=\mathrm{C}_{3} \mathrm{H}_{7}$<smiles>[R8][N+]([R8])([R])[B]</smiles>

Ammonium e.g. Cetrimonium $\mathrm{R}_{1,2,3}=\mathrm{CH}_{3^{\prime}}, \mathrm{R}_{4}=\mathrm{C}_{16} \mathrm{H}_{33}$<smiles>[R5][P+]([R])([R])[2H]</smiles>

Phosphonium e.g. $P_{6,6,14}$ $\mathrm{R}_{1,2,3}=\mathrm{C}_{6} \mathrm{H}_{13^{\prime}}, \mathrm{R}_{4}=\mathrm{C}_{14} \mathrm{H}_{25}$

Anions:<smiles>[13CH3]C(F)(F)S(=O)(=O)NS(=O)(=O)C(F)(F)F</smiles><smiles>O=S(=O)(F)[N-]S(=O)(=O)F</smiles>

Bis(trifluorosulfonyl)imide (TFSI)<smiles>[R]OP(=O)([O-])O[R]</smiles>
Phosphate e.g. Dibutylphosphate (DBP) e.g. Bis(2,4,4-trimethlpentyl)phosphinate<smiles>[R6]P([R])(=O)[O-]</smiles>
Bis(fluorosulfonyl)imide (FSI) $\mathrm{R}_{1,2}=\mathrm{C}_{4} \mathrm{H}_{9}$ $\mathrm{R}_{1,2}=\mathrm{C}_{2} \mathrm{H}_{3}\left(\mathrm{CH}_{3}\right) \mathrm{C}_{2} \mathrm{H}_{2}\left(\mathrm{CH}_{3}\right)_{3}$

Deep Eutectic Solvent:<smiles>C[N+](C)(Cl)CCO</smiles>

Cholinium Chloride<smiles>NC(N)=O</smiles>

Urea

Fig. 1 Typical ionic liquids and DES systems used in passivation of reactive metals

respect to stability even in dry environments due to their intrinsic acidity. ${ }^{27-30}$ With the discovery of the pyrrolidinium bis(trifluoromethane) sulfonamide (TFSI) family of ionic liquids, a study described by Howlett et al. revealed that ionic liquids could successfully support $>99 \%$ cycling efficiency of $\mathrm{Li}^{+/ 0}$ onto platinum and copper working electrodes without dendrite formation. ${ }^{31}$ Since then, ionic liquids have been intensively explored as candidates for safe battery electrolytes, providing different solvation of ions and large electrochemical stability. ${ }^{32,}{ }^{33}$ For several decades, researchers have been seeking to understand the formation and control of a beneficial SEl in batteries, particularly in those studies involving highly reactive metals, such as lithium in contact with an electrolyte, Fig. 2a-d. ${ }^{34,35}$ lonic liquids seem particularly promising in this respect, particularly those containing fluorinated anions.

For example in Fig. 2e, $f, g$, very recently it was shown that in the IL $\mathrm{C}_{3}$ mPyrFSI (i.e., $N$-methyl- $N$-propylpyrrolidinium bis(fluorosulfonyl)imide-Fig. 1), the pretreated SEI formed chemically prior to cycling has been characterised and shows long cycle lifetimes are possible in a full cell arrangement vs. $\mathrm{LiFePO}_{4}{ }^{8}$ The SEl formed upon lithium metal in that cell arrangement is made up of $\mathrm{LiF}, \mathrm{LiOH}, \mathrm{Li}_{2} \mathrm{~S}, \mathrm{LiSO}_{2} \mathrm{~F}$ and $\mathrm{NSO}^{-}$species. This was also hinted at in the earlier work by us. ${ }^{36}$ These compounds come about after the initial formation of LiF that produces an intermediate radical ion, $\mathrm{SO}_{2} \mathrm{NSO}_{2} \mathrm{~F}$, which persists at the surface for adequate time to undergo further reduction. ${ }^{37}$ Evidence for ring opening of the cation is also observed within the interphase, which can be explained by a $\beta$-Hofmann elimination taking place. $^{38}$ These products passivate the reactive lithium metal, limiting further corrosion of the anode while permitting the ingress and egress of the charge carrying $\mathrm{Li}^{+}$during battery operation. The preparation of an SEI in this manner through chemical/electrochemical pathways is facile, and less expensive than recent physical techniques. Interestingly, these reactions are reminiscent of those that are proposed to occur on other reactive engineering alloys, such as magnesium and aluminium, where the reduction of the anion (either TFSI or organophosphate) and subsequent deposition of the metal salt on the surface leads to a passivating layer ${ }^{39,} 40$ as will be discussed in a later section.

An additional component to the formation of this invaluable interphase is the degree of adventitious moisture within the ionic liquid electrolyte. Recent reports have detailed the large role moisture can play in the formation of a beneficial SEl for both lithium ${ }^{41}$ and sodium metal anodes. ${ }^{42}$ Electrochemical characterisation of these interphases shows an increased polarisation during symmetrical cell cycling, which is attributed to a larger impedance of the electrode-electrolyte interphase. In case of passivation against corrosion of $\mathrm{Mg}$ or $\mathrm{Al}$, low concentrations (0.1 $\mathrm{wt} \%$ ) of acid have also shown to be beneficial. ${ }^{40}$

Investigations of highly concentrated ionic liquid electrolytes (approaching $50 \mathrm{~mol} \%$ salt, Fig. $2 \mathrm{~h}$ ) have revealed interesting results in line with reports for more conventional electrolytes. ${ }^{43}$ When using such highly concentrated lithium electrolytes composed of a LiFSI salt in a phosphonium-based ionic liquid, $\mathrm{P}_{1111_{4}} \mathrm{FSI}$, we have demonstrated that the resultant interphase permits an extensive amount of lithium to be plated and stripped 
a

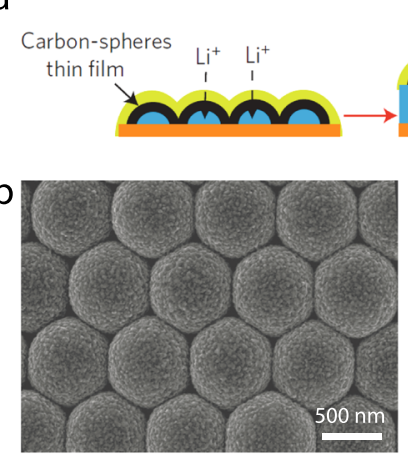

e
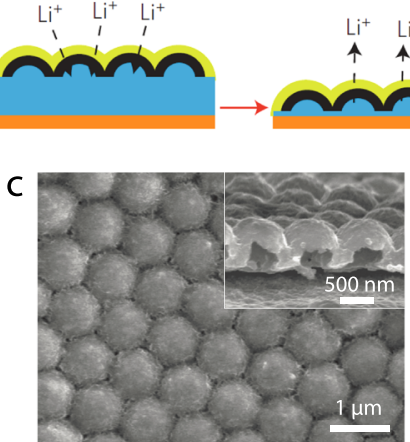

(i) Electrode polish vacuum dry (ii) SEl formation

(time sensitive)
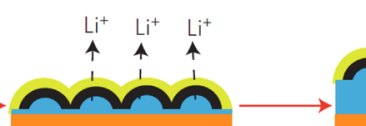

$\mathrm{h}_{1.0}$
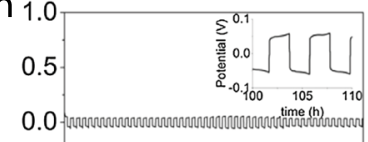

$-0.5$
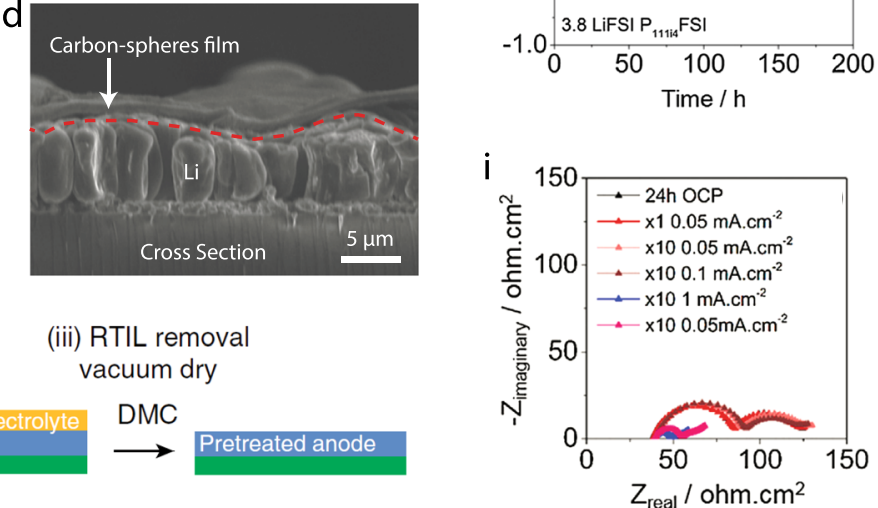

(iii) RTIL removal vacuum dry

\section{DMC}

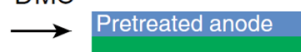

$f$<smiles>C=CCC[C@@H]1CC[In]1</smiles>

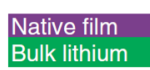

$\longrightarrow$
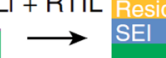
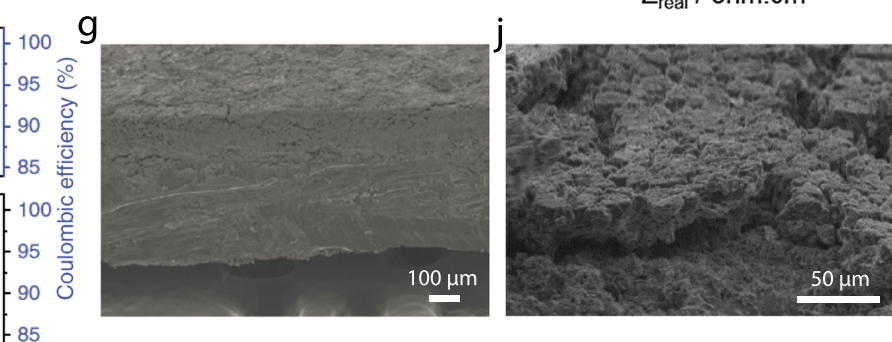

Fig. 2 Recent developments in the preparation of stable interphases at reactive metal electrodes. a Schematic diagram of the ingress/egress of lithium through a hollow carbon nanosphere scaffold SEl. Scanning electron micrographs of the scaffold before (b) and after (c) lithium plating and stripping and $\mathbf{d}$ cross-section after lithiation. e Schematic diagram of time-dependant SEl formation via facile chemical treatment prior to cell fabrication. $f$ Cycling behaviour of LilLiFePO 4 cells comparing lithium anodes, pretreated SEI surface (red boxes) vs. a pristine foil (blue boxes). $\mathbf{g}$ Cross-section micrograph of the ionic liquid pretreated lithium foil after cycling shown in $\mathbf{f}$. $\mathbf{h}$ Voltage-time profile for a LilLi cell when using highly concentrated ionic liquids at high current density exhibiting low polarisation $\left(0.1 \mathrm{~V}, 3 \mathrm{mAh} \mathrm{cm}^{-2}\right)$ and micrographs of the resultant surface morphology (i) and cross-section (j). Figure reproduced/adapted with permission from: a, b, c, d, ref. 35 Macmillan Publishers Ltd; e, f, g, ref. 8 Macmillan Publishers Ltd; $\mathbf{h}, \mathbf{i}, \mathbf{j}$, ref. 9, Elsevier Ltd.

at high current density for extended duration (up to $6 \mathrm{mAh}$ $\left.\mathrm{cm}^{-2}\right) .{ }^{9}, 44$ This is also the case in the $\mathrm{P}_{11144} \mathrm{FSI}^{45}$ and also the analogous $\mathrm{P}_{1 \text { i4i4i4 }} \mathrm{FSI}^{46}$ ionic liquid when using up to $50 \mathrm{~mol} \%$ $\mathrm{NaFSI}$. Initial electrochemical characterisation of the interphase formed in these systems has shown low electrode-electrolyte impedance. Work is underway to more extensively characterise this interphase, as it is seen as critical for controlling $\mathrm{Na}$ electrochemistry by halting corrosive side reactions while still allowing $\mathrm{Na}^{+}$transport during battery operation.

lonic liquid generated SEI layers are also critically relevant in the cycling of $\mathrm{Mg}$ anodes in ionic liquid-based $\mathrm{Mg}$-metal battery electrolytes. ${ }^{47}$ In this case, it has recently become clear that small amounts of water in the electrolyte can play a more dominating role in the formation and properties of the SEl; the predominately MgO-type surface layer, being quite strongly passivating, rapidly quenches the activity of the anode during cycling. ${ }^{48}$ The recent work has shown that chemical removal of these residual amounts of water allows extended cycling of $\mathrm{Mg}$ in the IL electrolyte, with a very thin, more IL-dominated SEl layer probably allowing transport of $\mathrm{Mg}$ to and from the $\left[\mathrm{NTf}_{2}\right]^{-}$-based IL electrolyte. On the other hand, when FSI was used as the anion, passivation was observed and X-ray powder diffraction revealed the formation of $\mathrm{MgF}_{2}{ }^{47}$

The same behaviour has been demonstrated for Mg primary batteries where a phosphonium chloride ionic liquid, with either water or ethylene glycol additives, can sustain controlled discharge when a current is drawn but otherwise passivates the magnesium surface, thus preventing corrosion and self-discharge, through the formation of a complex magnesium chloride gel in which the phosphonium IL cation is also contained. ${ }^{49,} 50$

The work described above demonstrates that the effect of impurities/additives on the surface electrochemistry and the interphase layer on reactive metals is an ongoing research challenge and possibly a practical opportunity. ${ }^{40}$

Ionic liquid-derived protective/passivating surface films on $\mathrm{Mg}$ and Al alloys

As a protective surface treatment, ionic liquids have been investigated predominantly for magnesium, but also on aluminium alloys. ${ }^{13,16,51}$ The reader is referred to a review by Huang et al. in 2013, which summarises the state of the art at that point. Briefly, following on from the SEl formation on reactive metals, such as lithium, it was shown that immersion of $\mathrm{Mg}$ alloys in an anionic liquid containing TFSI as the anion also led to the formation of a protective surface film. A combination of surface techniques indicated that the films are likely composed of a Mg (or Al) salt containing the breakdown of the IL anion, with IL cation somehow entrained in this film. Various parameters have been investigated, such as ionic liquid structure, concentration, the effect of dilution in a solvent, temperature, bias voltage and surface pickling. Many of these treatments are employed to homogenise the surface and encourage a uniform reaction layer between the IL and the surface to increase the level of protection. While the fluoride salts that formed on a Mg surface immersed in a 
TFSI IL offered almost a 100-fold protection against corrosion in a chloride containing solution, it was quickly shown that ionic liquids containing the phosphate or phosphonate anion were significantly more protective, with thin compact protective films less than $100 \mathrm{~nm}$ forming on the surface under certain controlled conditions (see Fig. 3). ${ }^{13,14,16}$ Interestingly, the uniformity of these films is enhanced by activation of the surface, either by using a potential bias (preferably anodic) or by heating the surface to between 50 and $100^{\circ} \mathrm{C}{ }^{12,} 52$ In both activated cases, the application of a potential or high temperature renders the alloy surface more reactive and thus metal oxidation occurs more rapidly, releasing for example $\mathrm{Mg}^{2+}$ ions near the surface, which then react with the nearby anions forming a surface film. This appears to be a more uniform process under the activated conditions, rather than metal oxidation and hence subsequent film deposition occurring at localised grain boundaries or next to secondary phases/intermetallic particles. ${ }^{12}$ The surface properties of this film are significantly modified as can be seen from Fig. 3c, which shows the contact angle decreasing significantly as a more uniform protective interphase forms (Fig. 3).

Ionic liquid corrosion inhibitors and antimicrobials for steel Ionic liquids have also been used as corrosion inhibitors to form a protective surface film on metal surfaces, predominantly for mild steel in acidic solutions, but also for a range of other metals, such as aluminium and magnesium. ${ }^{15,53-57}$ Seen as an environmentally friendlier alternative to traditional corrosion inhibitors, particularly those that included the highly effective but highly toxic chromium $\mathrm{VI}$, ionic liquids have been used in solution and as a surface treatment prior to immersion in an aggressive solution. In solution, certain structural properties have been identified that enhance the surface protection offered by these compounds. The presence of $\pi$ electrons from double, triple or aromatic bonds and free electrons from elements, such as nitrogen, encourage adsorption at the surface, displacing water to form a protective film. ${ }^{15}, 54$ Consequently, for steel and aluminium, imidazolium cations have been most widely used, some even with benzyl groups attached to increase adsorption. Extended alkyl chain length has also been proposed to increase the strength of adsorption, either on the imidazolium or through the use of quaternary ammoniums. ${ }^{55}$

While many of these studies have shown the effect of the cation structure, the effect of the anion structure does not appear to be as clear. Many of the ILs investigated consisted of a simple anion, such as chloride or bromide. When compared to more complex anion structures, such as bis(trifluoromethanesulfonyl)amide, the simpler anions have often shown a comparable or better performance. $^{53}, 56,57$ More recently Chong et al. showed a synergistic effect in the performance of an imidazolinium cinnamate, which at a pH of 2 clearly outperformed the imidazolinium chloride and the sodium cinnamate in protecting a mild steel surface (Fig. $4 a-c$ ). ${ }^{58}$ This type of material is being referred to as a dual active IL, in which both the cation and anion contribute to the performance. In fact the imidazolinium cinnamate was designed to combat microbially influenced corrosion (MIC), with the imidazolinium cation proposed to inhibit microbial growth, while the cinnamate inhibits corrosion. Since a number of the compounds likely to inhibit microbial growth are similar in structure to corrosion inhibitors, such as quaternary ammoniums and imidazoles, dual active ILs for MIC inhibition have been proposed. Seter et al. investigated a range of ILs as MIC inhibitors. It was found that cetrimonium nalidixate was the most effective inhibitor of microbial growth (Fig. 4d) and was able to prevent both biofilm formation and the initiation of pitting corrosion. ${ }^{59,} 60$ Thus, the prospect of designing ionic liquids (or indeed organic salts which are based on similar ion chemistry and structure) to target both corrosion inhibition and MIC as dual actives is an area ripe for further investigation, given the diversity a
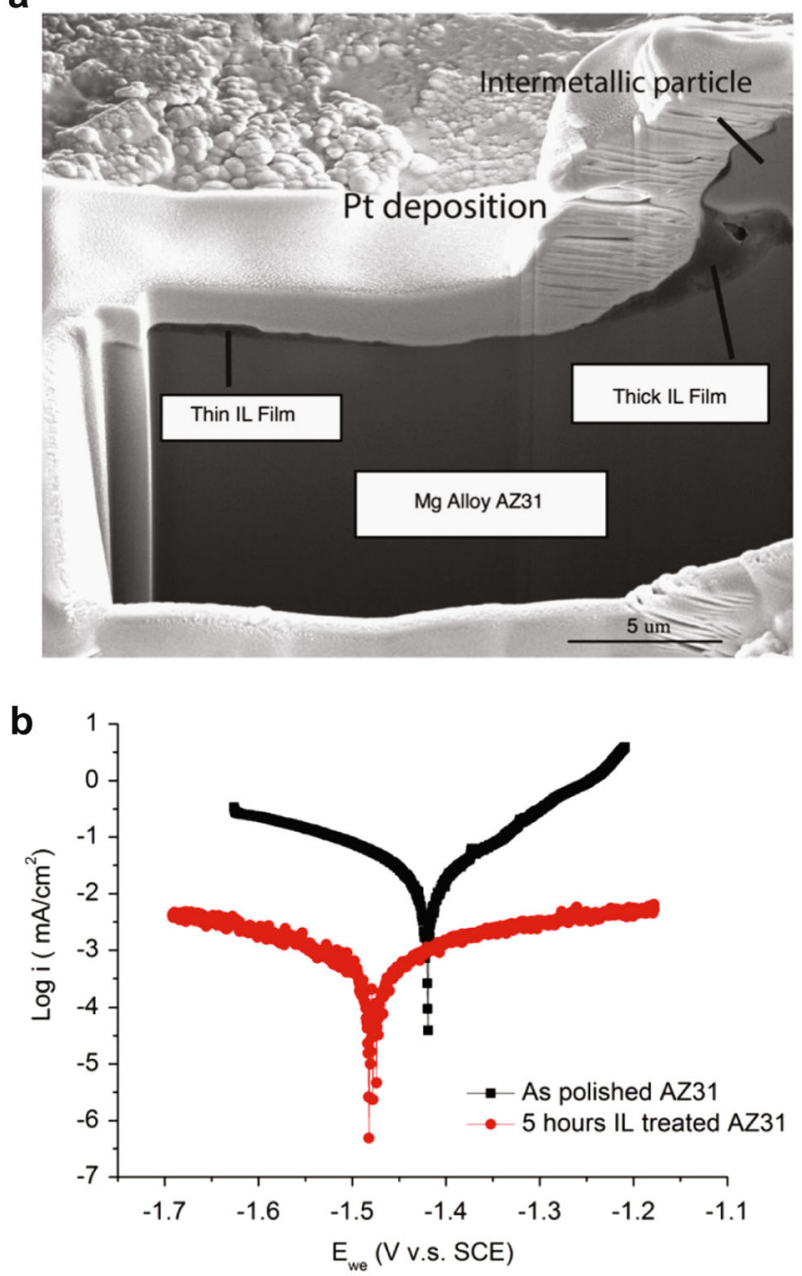

C

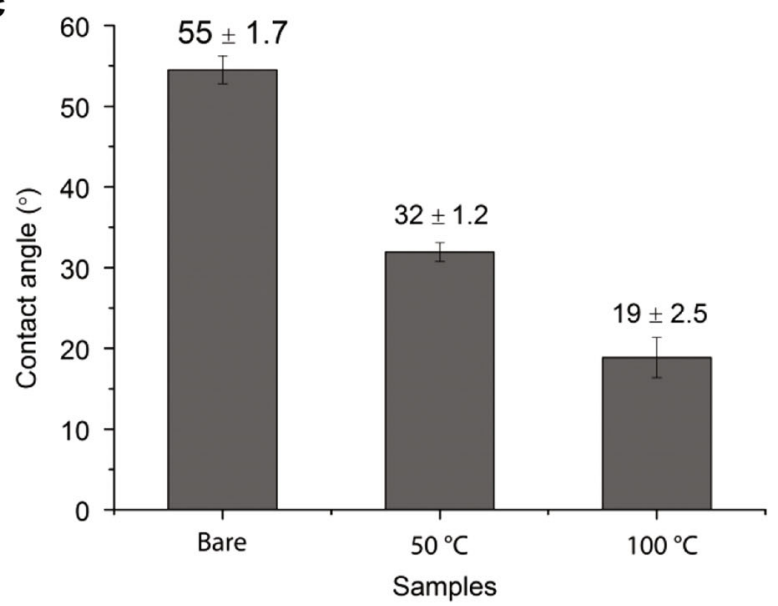

Fig. 3 a Scanning electron microscope (SEM) image of a FIB crosssection specimen of $A Z 31$ treated with $P_{1444} \mathrm{dpp} \mathbf{b}$ polarisation date for same AZ31 alloy immersed in a simulated body fluid c contact angle for water on bare AZ31 and surface immersed in $\mathrm{P}_{1444} \mathrm{dpp}$ at 50 and $100{ }^{\circ} \mathrm{C}$. Thicker deposit can be seen near the intermetallic. The polarisation data shows two orders of magnitude reduction in anodic and cathodic current densities. Figure reproduced/adapted with permission from: a, b ref. 16, Elsevier Ltd. c Reprinted with permission from ACS Applied Materials and Interfaces, 2014. 6(21): p. 18989-18997. Copyright 2014 American Chemical Society ref. 52. 

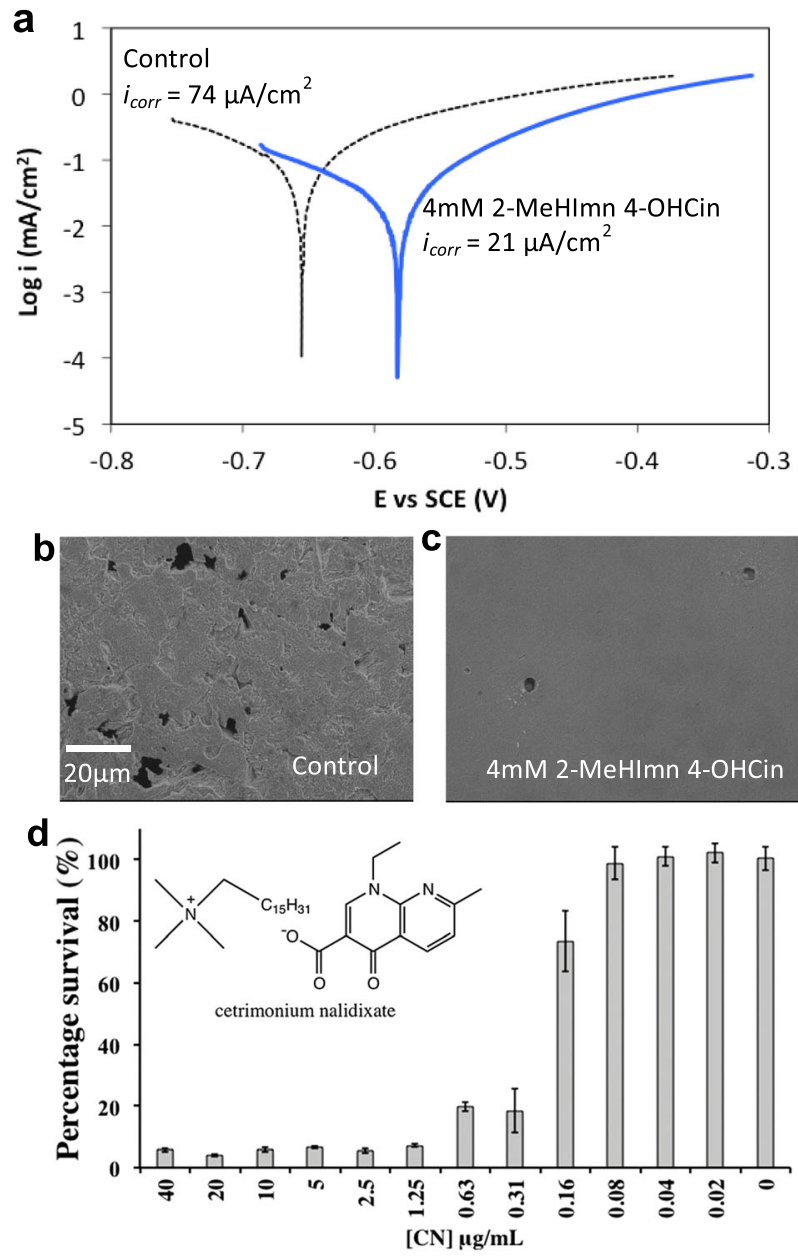

Fig. 4 Performance of ILs as corrosion and microbial inhibitors. a Potentiodynamic polarisation results for mild steel in $0.01 \mathrm{M} \mathrm{NaCl}$ at $\mathrm{pH} 2$ after $30 \mathrm{~min}$ with and without $4 \mathrm{mM}$ of 2-methylimidazolinium 4-hydroxycinnamate. SEM images of mild steel immersed for $24 \mathrm{~h}$ in $0.01 \mathrm{M} \mathrm{NaCl}$ at $\mathrm{pH} 2$ b control and $\mathbf{c}$ with $4 \mathrm{mM}$ 2-MeHImn 4-OHCin. d Shows the percentage survival of the bacteria Vibrio alginolyticus in the presence of cetrimonium nalidixate. a, b, c Reprinted with permission from ACS Sustainable Chemistry \& Engineering, 2016. 4 (3): p. 1746-1755. Copyright 2016 American Chemical Society ref. 58. d Figure reproduced/adapted with permission from ref. 60, Royal Society of Chemistry.

of chemistry available and the literally millions of combinations of anion and cation that are possible.

\section{Future prospects}

Thus far, ionic liquids have clearly demonstrated their potential for controlling electrochemical reactions on either engineering alloys or battery anode materials, although understanding the chemistry of the interphases is still in its infancy. That there is a role for the anion chemistry in particular, and the presence of impurities or the deliberate addition of reactive small components such as water, halides or acid, is evident from the research thus far. However, the precise chemical mechanisms are far from well understood in order to enable strategic design of interphases. The use of advanced surface characterisation methods to understand the composition and morphology of these interphases and their relationship to IL composition and processing conditions will help develop this field further. Specifically, the development of methodologies to observe the formation and propagation of these films in situ is a key area of research required to drive IL design for interphase control.

Furthermore, the possibility of designing dual active ILs that can protect against corrosion and antifouling is also attractive. The scope for new chemistry in this case is only just emerging and the DES systems may offer an additional, more economical alternative in this space.

Finally, little work has been done on other reactive surfaces, such as $\mathrm{Cu}, \mathrm{Zn}$ or ZincAlum (of key importance with respect to galvanised steel for example). Designing task-specific ILs to create a unique protective surface for a given metal or metal alloy or indeed to enable new battery chemistries offer exciting possibilities. It is hoped that the ideas in this perspective will trigger further research in chemical design, mechanistic understanding and novel surface modification to engineer interphases using novel IL and DES materials.

\section{ACKNOWLEDGEMENTS}

The authors acknowledge the ARC (Australian Research Council) for its financial support. The authors acknowledge the ARC for funding through Australian Laureate Fellowship FL110100013 (M.F.) and FL120100019 (D.R.M.) and under Australian Research Council's Discovery Projects funding scheme (DP160101178).

\section{AUTHOR CONTRIBUTIONS}

M.F. and P.C.H. conceived and designed the perspective. All authors discussed the relevant literature and co-wrote the manuscript. D.R.M. and M.F. edited the manuscript.

\section{ADDITIONAL INFORMATION}

Competing interests: The authors declare that they have no competing financial interests.

Publisher's note: Springer Nature remains neutral with regard to jurisdictional claims in published maps and institutional affiliations.

\section{REFERENCES}

1. Hallett, J. P. \& Welton, T. Room-temperature ionic liquids: solvents for synthesis and catalysis. 2. Chem. Rev. 111, 3508-3576 (2011).

2. Wang, B., Qin, L., Mu, T., Xue, Z. \& Gao, G. Are ionic liquids chemically stable? Chem. Rev. 117, 7113-7131 (2017).

3. Brennecke, J. F. \& Maginn, E. J. Ionic liquids: innovative fluids for chemical processing. AlChE J. 47, 2384-2389 (2001).

4. Cui, G., Wang, J. \& Zhang, S. Active chemisorption sites in functionalized ionic liquids for carbon capture. Chem. Soc. Rev. 45, 4307-4339 (2016).

5. Somers, A., Howlett, P., MacFarlane, D. \& Forsyth, M. A review of ionic liquid lubricants. Lubricants 1, 3-21 (2013).

6. Somers, A. E. et al. lonic liquids as antiwear additives in base oils: influence of structure on miscibility and antiwear performance for steel on aluminum. ACS Appl. Mater. Interfaces 5, 11544-11553 (2013).

7. Zhou, F., Liang, Y. \& Liu, W. lonic liquid lubricants: designed chemistry for engineering applications. Chem. Soc. Rev. 38, 2590-2599 (2009).

8. Basile, A., Bhatt, A. I. \& O'Mullane, A. P. Stabilizing lithium metal using ionic liquids for long-lived batteries. Nat. Commun. 7, 11794 (2016).

9. Forsyth, M. et al. Inorganic-organic ionic liquid electrolytes enabling high energydensity metal electrodes for energy storage. Electrochim. Acta 220, 609-617 (2016).

10. MacFarlane, D. R. et al. Energy applications of ionic liquids. Energy Environ. Sci. 7, 232-250 (2014).

11. Watanabe, M. et al. Application of ionic liquids to energy storage and conversion materials and devices. Chem. Rev. 117, 7190-7239 (2017).

12. Efthimiadis, J. et al. Potentiostatic control of ionic liquid surface film formation on ZE41 magnesium alloy. ACS Appl. Mater. Interfaces 2, 1317-1323 (2010).

13. Huang, P., Latham, J. A., Macfarlane, D. R., Howlett, P. C. \& Forsyth, M. A review of ionic liquid surface film formation on $\mathrm{Mg}$ and its alloys for improved corrosion performance. Electrochim. Acta 110, 501-510 (2013).

14. Latham, J. A., Howlett, P. C., MacFarlane, D. R., Somers, A. \& Forsyth, M. Anodising AZ31 in a phosphonium ionic liquid: corrosion protection through composite film deposition. J. Electrochem. Soc. 159, C539-C545 (2012). 
15. Verma, C., Ebenso, E. E. \& Quraishi, M. A. Ionic liquids as green and sustainable corrosion inhibitors for metals and alloys: an overview. J. Mol. Liq. 233, 403-414 (2017).

16. Zhang, Y. et al. The effect of treatment time on the ionic liquid surface film formation: promising surface coating for Mg alloy AZ31. Surf. Coat. Technol. 296, 192-202 (2016).

17. Kumar, A., Bisht, M. \& Venkatesu, P. Exploring the structure and stability of amino acids and glycine peptides in biocompatible ionic liquids. RSC Adv. 6, 18763-18777 (2016)

18. Diamanti, M. V. et al. Compatibility of imidazolium-based ionic liquids for $\mathrm{CO} 2$ capture with steel alloys: a corrosion perspective. Electrochim. Acta 192, 414-421 (2016).

19. Dilasari, B., Jung, Y. \& Kwon, K. Comparative study of corrosion behavior of metals in protic and aprotic ionic liquids. Electrochem. Commun. 73, 20-23 (2016).

20. Zhang, Q., Vigier, K. D. O., Royer, S. \& Jérôme, F. Deep eutectic solvents: syntheses, properties and applications. Chem. Soc. Rev. 41, 7108-7146 (2012).

21. Smith, E. L., Abbott, A. P. \& Ryder, K. S. Deep eutectic solvents (DESs) and their applications. Chem. Rev. 114, 11060-11082 (2014).

22. Fuller, J., Carlin, R. T. \& Osteryoung, R. A. The room temperature ionic liquid 1ethyl-3-methylimidazolium tetrafluoroborate: electrochemical couples and physical properties. J. Electrochem. Soc. 144, 3881-3886 (1997).

23. Koch, V. R., Nanjundiah, C., Appetecchi, G. B. \& Scrosati, B. The interfacial stability of Li with two new solvent-free ionic liquids: 1,2-dimethyl-3-propylimidazolium imide and methide. J. Electrochem. Soc. 142, L116-L118 (1995).

24. Caja, J., Dunstan, T. D. J., Ryan, D. M. \& Katovic, V. in Molten Salts XII (eds Trulove, P. C., De Long, H. C., Stafford, G. R., \& Deki, S.) 150-160 (Electrochemical Society, 2000)

25. Sakaebe, H. \& Matsumoto, H. N-methyl-N-propylpiperidinium bis(trifluoromethanesulfonyl)imide (PP13-TFSI) - novel electrolyte base for Li battery. Electrochem. Commun. 5, 594-598 (2003).

26. Matsumoto, H. \& Miyazaki, Y. Yōyūen oyobi kōon kagaku 44, 7 (2001).

27. Wilkes, J. S., Levisky, J. A., Wilson, R. A. \& Hussey, C. L. Dialkylimidazolium chloroaluminate melts: a new class of room-temperature ionic liquids for electrochemistry, spectroscopy, and synthesis. Inorg. Chem. 21, 1263-1264 (1982).

28. Fuller, J. \& Osteryoung, R. A. Rechargeable lithium and sodium anodes in chloroaluminate molten salts containing thionyl chloride. J. Electrochem. Soc. 142, 3632-3636 (1995).

29. Piersma, B. J., Ryan, D. M., Schumacher, E. R. \& Riechel, T. L. Electrodeposition and stripping of lithium and sodium on inert electrodes in room temperature chloroaluminate molten salts. J. Electrochem. Soc. 143, 908-913 (1996).

30. Fung, Y. S. \& Zhou, R. Q. Room temperature molten salt as medium for lithium battery. J. Power Sources 81-82, 891-895 (1999).

31. Howlett, P. C., MacFarlane, D. R. \& Hollenkamp, A. F. High lithium metal cycling efficiency in a room-temperature ionic liquid. Electrochem. Solid-State Lett $\mathbf{7}$, A97-A101 (2004).

32. Armand, M., Endres, F., MacFarlane, D. R., Ohno, H. \& Scrosati, B. Ionic-liquid materials for the electrochemical challenges of the future. Nat. Mater. 8, 621-629 (2009).

33. Armand, M. \& Tarascon, J. M. Building better batteries. Nature. 451, 652-657 (2008).

34. Peled, E. Film forming reaction at the lithium/electrolyte interface. J. Power Sources 9, 253-266 (1983).

35. Zheng, G. et al. Interconnected hollow carbon nanospheres for stable lithium metal anodes. Nat. Nanotechnol. 9, 618-623 (2014).

36. Howlett, P. C., Brack, N., Hollenkamp, A. F., Forsyth, M. \& MacFarlane, D. R. Characterization of the lithium surface in $\mathrm{N}$-methyl-N-alkylpyrrolidinium bis(trifluoromethanesulfonyl)amide room-temperature ionic liquid electrolytes. J. Electrochem. Soc. 153, A595-A606 (2006).

37. Shkrob, I. A., Marin, T. W., Zhu, Y. \& Abraham, D. P. Why bis(fluorosulfonyl)imide is a "magic anion" for electrochemistry. J. Phys. Chem. C 118, 19661-19671 (2014).

38. Lane, G. H. Electrochemical reduction mechanisms and stabilities of some cation types used in ionic liquids and other organic salts. Electrochim. Acta 83, 513-528 (2012).

39. Forsyth, M. et al. New insights into the fundamental chemical nature of ionic liquid film formation on magnesium alloy surfaces. ACS Appl. Mater. Interfaces 1, 1045-1052 (2009).

40. Howlett, P. C. et al. Conversion coatings of Mg-alloy AZ91D using trihexyl(tetradecyl) phosphonium bis(trifluoromethanesulfonyl)amide ionic liquid. Sci. China Chem. 55, 1598-1607 (2012).

41. Yoon, $H$. et al. Lithium electrochemistry and cycling behaviour of ionic liquids using cyano based anions. Energy Environ. Sci. 6, 979-986 (2013).
42. Basile, A., Yoon, H., MacFarlane, D. R., Forsyth, M. \& Howlett, P. C. Investigating non-fluorinated anions for sodium battery electrolytes based on ionic liquids. Electrochem. Commun. 71, 48-51 (2016).

43. Qian, J. et al. High rate and stable cycling of lithium metal anode. Nat. Commun. 6, 6362 (2015).

44. Girard, G. M. A. et al. The role of Li concentration and the SEl layer in enabling high performance Li metal electrodes using a phosphonium bis(fluorosulfonyl) imide ionic liquid. J. Phys. Chem. C (2017) (in press).

45. Makhlooghiazad, F. et al. Phosphonium plastic crystal salt alloyed with a sodium salt as a solid-state electrolyte for sodium devices: phase behaviour and electrochemical performance. J. Mater. Chem. A 5, 5770-5780 (2017).

46. Basile, A. et al. Extensive sodium metal plating and stripping in a highly concentrated inorganic-organic ionic liquid electrolyte through surface pretreatment. ChemElectroChem 4, 986-991 (2017).

47. Kar, M. et al. Ionic liquid electrolytes for reversible magnesium electrochemistry. Chem. Commun. 52, 4033-4036 (2016).

48. Ma, Z., Kar, M., Xiao, C., Forsyth, M. \& MacFarlane, D. R. Electrochemical cycling of $\mathrm{Mg}$ in $\mathrm{Mg}[\mathrm{TFSI}]_{2}$ /tetraglyme electrolytes. Electrochem. Commun. 78, 29-32 (2017).

49. Khoo, T. et al. Discharge behaviour and interfacial properties of a magnesium battery incorporating trihexyl(tetradecyl)phosphonium based ionic liquid electrolytes. Electrochim. Acta 87, 701-708 (2013).

50. Yan, Y. et al. Investigating discharge performance and $\mathrm{Mg}$ interphase properties of an ionic liquid electrolyte based Mg-air battery. Electrochim. Acta 235, 270-279 (2017).

51. Sun, J., Howlett, P. C., MacFarlane, D. R., Lin, J. \& Forsyth, M. Synthesis and physical property characterisation of phosphonium ionic liquids based on $\mathrm{P}(\mathrm{O})_{2}(\mathrm{OR})_{2}-$ and $\mathrm{P}(\mathrm{O})_{2}(\mathrm{R})_{2}-$ anions with potential application for corrosion mitigation of magnesium alloys. Electrochim. Acta 54, 254-260 (2008).

52. Zhang, Y., Forsyth, M. \& Hinton, B. R. W. The effect of treatment temperature on corrosion resistance and hydrophilicity of an ionic liquid coating for $\mathrm{Mg}$-based stents. ACS Appl. Mater. Interfaces 6, 18989-18997 (2014).

53. Ashassi-Sorkhabi, H. \& Es'haghi, M. Corrosion inhibition of mild steel in acidic media by $[\mathrm{BM} I \mathrm{~m}] \mathrm{Br}$ ionic liquid. Mater. Chem. Phys. 114, 267-271 (2009).

54. Likhanova, N. V. et al. The effect of ionic liquids with imidazolium and pyridinium cations on the corrosion inhibition of mild steel in acidic environment. Corros. Sci. 52, 2088-2097 (2010).

55. Migahed, M. A. Electrochemical investigation of the corrosion behaviour of mild steel in $2 \mathrm{M} \mathrm{HCl}$ solution in presence of 1-dodecyl-4-methoxy pyridinium bromide. Mater. Chem. Phys. 93, 48-53 (2005).

56. Murulana, L. C., Singh, A. K., Shukla, S. K., Kabanda, M. M. \& Ebenso, E. E. Experimental and quantum chemical studies of some bis(trifluoromethyl-sulfonyl) imide imidazolium-based ionic liquids as corrosion inhibitors for mild steel in hydrochloric acid solution. Ind. Eng. Chem. Res. 51, 13282-13299 (2012).

57. Yousefi, A, Javadian, S. Dalir, N. Kakemam, J. \& Akbari, J. Imidazolium-based ionic liquids as modulators of corrosion inhibition of SDS on mild steel in hydrochloric acid solutions: experimental and theoretical studies. RSC Adv 5, 11697-11713 (2015).

58. Chong, A. L., Mardel, J. I., Forsyth, M., MacFarlane, D. R. \& Somers, A. E. Synergistic corrosion inhibition of mild steel in aqueous chloride solutions by an imidazolinium carboxylate salt. ACS Sustainable Chem. Eng. 4, 1746-1755 (2016).

59. Seter, M., Thomson, M. J., Chong, A., MacFarlane, D. R. \& Forsyth, M. Cetrimonium nalidixate as a multifunctional inhibitor to combat biofilm formation and microbiologically influenced corrosion. Aust. J. Chem. 66, 921-929 (2013).

60. Seter, M., Thomson, M. J., Stoimenovski, J., MacFarlane, D. R. \& Forsyth, M. Dual active ionic liquids and organic salts for inhibition of microbially influenced corrosion. Chem. Commun. 48, 5983-5985 (2012).

Open Access This article is licensed under a Creative Commons Attribution 4.0 International License, which permits use, sharing, adaptation, distribution and reproduction in any medium or format, as long as you give appropriate credit to the original author(s) and the source, provide a link to the Creative Commons license, and indicate if changes were made. The images or other third party material in this article are included in the article's Creative Commons license, unless indicated otherwise in a credit line to the material. If material is not included in the article's Creative Commons license and your intended use is not permitted by statutory regulation or exceeds the permitted use, you will need to obtain permission directly from the copyright holder. To view a copy of this license, visit http://creativecommons. org/licenses/by/4.0/.

(c) The Author(s) 2017 